\title{
Antioxidant Effects of Quercetin and Naringenin Are Associated with Impaired Neutrophil Microbicidal Activity
}

\author{
Francielli de Cássia Yukari Nishimura, ${ }^{1}$ Ana Carolina de Almeida, ${ }^{2}$ \\ Bianca Altrão Ratti, ${ }^{1}$ Tânia Ueda-Nakamura, ${ }^{1}$ Celso Vataru Nakamura, ${ }^{1}$ \\ Valdecir Farias Ximenes, ${ }^{2}$ and Sueli de Oliveira Silva ${ }^{1}$ \\ ${ }^{1}$ Departamento de Ciências Básicas da Saúde, Universidade Estadual de Maringá, Avenida Colombo 5.790, \\ 87020-900 Maringá, PR, Brazil \\ ${ }^{2}$ Departamento de Química, Faculdade de Ciências, Universidade Estadual Paulista, Avenida Eng. Luiz Edmundo Carrijo Coube 14-01, \\ 17033-360 Bauru, SP, Brazil
}

Correspondence should be addressed to Sueli de Oliveira Silva; lautenschlager@uem.br

Received 3 April 2013; Revised 16 May 2013; Accepted 18 June 2013

Academic Editor: Chong-Zhi Wang

Copyright (C) 2013 Francielli de Cássia Yukari Nishimura et al. This is an open access article distributed under the Creative Commons Attribution License, which permits unrestricted use, distribution, and reproduction in any medium, provided the original work is properly cited.

\begin{abstract}
Naringenin and quercetin are considered antioxidant compounds with promising activity against oxidative damage in human cells. However, no reports have described their effects on reactive oxygen species (ROS) production by phagocytes during microbicidal activity. Thus, the present study evaluated the effects of naringenin and quercetin on ROS production, specifically hypochlorous acid $(\mathrm{HOCl})$, and their involvement in the microbicidal activity of neutrophils. Naringenin and quercetin inhibited HOCl production through different systems, but this inhibition was more pronounced for quercetin, even in the cell-free systems. With regard to the microbicidal activity of neutrophils, both naringenin and quercetin completely inhibited the killing of Staphylococcus aureus. Altogether, these data indicate that the decrease in the oxidant activity of neutrophils induced by these compounds directly impaired the microbicidal activity of neutrophils. Naringenin and quercetin exerted their effects by controlling the effector mechanisms of ROS production, with both positive and negative effects of these antioxidant agents in oxidative stress conditions and on ROS in the microbicidal activity of phagocytes. The present results challenge the traditional view of antioxidants as improvers of pathological conditions.
\end{abstract}

\section{Introduction}

Accumulating evidence indicates the involvement of reactive oxygen species (ROS) in different physiological functions and various cell signaling processes, including reproduction, cell migration, stem cell proliferation, neurogenesis, and phagocytosis [1-5]. Depending on the intracellular concentration of ROS, they can contribute to both physiological and pathological conditions. The long-term exposure of cells to enhanced levels of ROS is involved in the pathogenesis of many human diseases, including chronic inflammation, neurodegenerative disorders, and some cancers, by damaging essential molecules, such as lipids, proteins, and DNA [6-9]. Thus, maintaining an appropriate balance between ROS and antioxidant enzymes is important to avoid deleterious processes.
New effective therapies based on exogenous antioxidants have been sought $[10,11]$. Although the literature presents various compounds obtained from plants with promising antioxidant effects, few studies have examined the side effects of these substances on physiological functions that depend on ROS.

For example, an increasing number of studies have investigated different types of flavonoids with antioxidant potential. Most of these studies have indicated that flavonoids are promising immunomodulators, with direct antioxidant effects that involve ROS scavenging [11, 12] and anti-inflammatory effects, reflected by a reduction of the activity of ROS-forming enzymes, such as NADPH oxidase and myeloperoxidase (MPO) [13]. However, there is growing recognition of the importance of ROS, especially 
hypochlorous acid $(\mathrm{HOCl})$, produced by phagocytes through NADPH oxidase in microbicidal activity $[14,15]$. In addition to microbicidal activity, ROS produced by NADPH oxidase has emerged as an important messenger of several cellular signaling pathways, including the activation of nuclear transcription factors such as NF- $\kappa$ B and AP-1 that are associated with physiological functions involving, respectively, inflammatory responses and the expression of protective genes that repair damaged DNA, [16].

Considering that the production of ROS by the NADPH oxidase system is an initial and critical event for the onset of oxidative stress conditions and microbicidal activity, the present study investigated the effects of quercetin and naringenin on the production of ROS, especially $\mathrm{HOCl}$, and their involvement in the microbicidal activity of neutrophils. We sought to determine whether the antioxidant effects of quercetin and naringenin are associated with impaired neutrophil function.

\section{Materials and Methods}

2.1. Chemicals. Quercetin, naringenin, dextran, taurine, 3,3',5,5' -tetramethylbenzidine (TMB), hydrogen peroxide, $\mathrm{MPO}$, catalase, phorbol 12-myristate 13-acetate (PMA), dimethyl sulfoxide (DMSO), and Histopaque were obtained from Sigma (St. Louis, MO, USA). Naringenin and quercetin stock solutions $(2.5 \mathrm{mM})$ were prepared in DMSO, stored at $8^{\circ} \mathrm{C}$, and used within 1 week. Dimethyl sulfoxide was added at the same concentration in all of the samples including the controls at a final concentration of $0.2 \%$, a concentration that has been shown to not affect neutrophil viability.

2.2. Neutrophils and Total Leukocytes. Neutrophils and total leukocytes were isolated from peripheral venous blood obtained from healthy volunteers by centrifugation over a Ficoll-Hypaque gradient (Histopaque; $d=1.077$ ) [17, 18]. Cell concentration and viability were determined in a Neubauer chamber. Neutrophils $\left(2.5 \times 10^{6}\right.$ cells $\left./ \mathrm{mL}\right)$ and total leukocytes $\left(2.0 \times 10^{6}\right.$ cells $\left./ \mathrm{mL}\right)$ were suspended in $10 \mathrm{mM}$ phosphate-buffered saline (PBS; $\mathrm{pH} 7.4$ ) supplemented with $1 \mathrm{mg} / \mathrm{mL}$ glucose, $1 \mathrm{mM} \mathrm{CaCl}_{2}$, and $0.5 \mathrm{mM} \mathrm{MgCl}_{2}$.

\subsection{Effects of Quercetin and Naringenin on HOCl Production.} The concentration of $\mathrm{HOCl}$ produced in cellular and cell-free systems was evaluated according to the method described by Dypbukt et al. [19]. Briefly, $\mathrm{HOCl}$ was trapped as the less reactive and stable taurine chloramine. Taurine chloramine in the supernatant was then quantified by the oxidation of TMB (10 mM in 1:1 [v/v] dimethylformamide/0.8 M acetic acid, containing $100 \mu \mathrm{M}$ potassium iodide) to a blue product with maximum absorbance at $655 \mathrm{~nm}$. A calibration curve that consisted of pure $\mathrm{HOCl}$ was generated to calculate the production of the oxidant. The analyses were performed in a final volume of $250 \mu \mathrm{L}$ using a microplate reader spectrophotometer (Biotec power-WaveX5, USA). The effects of naringenin and quercetin on $\mathrm{HOCl}$ production were studied using three different experimental models.
2.3.1. Cell-Free System: Antioxidant Effects of Naringenin and Quercetin. A 96-well culture plate that contained $50 \mu \mathrm{M}$ $\mathrm{HOCl}$ and $5 \mathrm{mM}$ taurine in supplemented PBS was incubated in the presence or absence of naringenin and quercetin (25 and $50 \mu \mathrm{M}$ ) for $10 \mathrm{~min}$ at $25^{\circ} \mathrm{C}$. The final volume was $200 \mu \mathrm{L}$, and the reactions were triggered by adding $\mathrm{HOCl}$. The TMB solution $(50 \mu \mathrm{L})$ was then added to measure the remaining taurine chloramine.

2.3.2. Cell-Free System: Effects of Naringenin and Quercetin on $\mathrm{HOCl}$ Production by MPO/Hydrogen Peroxide $\left(\mathrm{H}_{2} \mathrm{O}_{2}\right) / \mathrm{Cl}^{-}$. A 96-well culture plate that contained MPO (65 nM), $5 \mathrm{mM}$ taurine, and $50 \mu \mathrm{M} \mathrm{H}_{2} \mathrm{O}_{2}$ in supplemented PBS was incubated in the presence or absence of quercetin and naringenin (25 and $50 \mu \mathrm{M}$ ) for $10 \mathrm{~min}$ at $25^{\circ} \mathrm{C}$. The reactions were triggered by adding $\mathrm{H}_{2} \mathrm{O}_{2}$ and stopped by adding catalase $(65 \mu \mathrm{g} / \mathrm{mL})$. The final volume was $200 \mu \mathrm{L}$. The TMB solution $(50 \mu \mathrm{L})$ was then added to the samples, and $\mathrm{HOCl}$ production was quantified. The positive control, without the tested substances, was used to calculate the inhibitory effect.

2.3.3. Effects of Naringenin and Quercetin on HOCl Production by Neutrophils. Neutrophils $\left(1.0 \times 10^{6}\right.$ cells $\left./ \mathrm{mL}\right)$ were preincubated in the presence or absence of quercetin and naringenin $(25$ and $50 \mu \mathrm{M})$ in supplemented PBS that contained $5 \mathrm{mM}$ taurine for $10 \mathrm{~min}$ at $37^{\circ} \mathrm{C}$. All of the samples were then incubated with PMA $(6.65 \mu \mathrm{g} / \mathrm{mL})$ for $30 \mathrm{~min}$ at $37^{\circ} \mathrm{C}$. Afterward, the reactions were stopped by adding catalase $(65 \mu \mathrm{g} / \mathrm{mL})$. The final volume was $200 \mu \mathrm{L}$. The cells were pelleted by centrifugation $\left(1,200 \times \mathrm{g}\right.$ for $10 \mathrm{~min}$ at $\left.24^{\circ} \mathrm{C}\right)$, and $\mathrm{HOCl}$ production was quantified as stated previously.

2.4. Effects of Naringenin and Quercetin on ROS Production by Leukocytes. Dihydrorhodamine 123 (DHR) is widely used for the detection of intracellular oxidant species production by cell systems [20]. The oxidation of DHR by ROS results in the formation of rhodamine, a highly fluorescent component. Total leukocytes $\left(2.0 \times 10^{6}\right.$ cells $\left./ \mathrm{mL}\right)$ were incubated with quercetin or naringenin $(10$ and $100 \mu \mathrm{M})$ for $2 \mathrm{~h}$ and then stimulated with PMA (400 nM) for $10 \mathrm{~min}$. After PMA stimulation, the cells were incubated with DHR $(10 \mathrm{mg} / \mathrm{mL})$ for 5 min, washed once with PBS, and suspended in PBS/bovine serum albumin/azide buffer. The fluorescence of gated neutrophils was detected at FL1, counting 30,000 events/gate, in a FACS Canto Flow Cytometer (BD, Franklin Lakes, NJ, USA). The data were analyzed using Flow Cytometry Analysis software (Treestar, Ashland, OR, USA), and the results are expressed as the fluorescence intensity and percentage of positive cells in the sample.

\subsection{Effects of Naringenin and Quercetin on Microbicidal Assay}

2.5.1. Growth and Opsonization of Bacteria. Staphylococcus aureus (ATCC-25923) was grown overnight on nutrient agar plates at $37^{\circ} \mathrm{C}$. The cell colonies were scraped and suspended in sterile PBS $(10 \mathrm{mM})$, and the number of viable cells was estimated by measuring the optical density at $550 \mathrm{~nm}\left(\mathrm{OD}_{550}\right)$ using suitable calibration curves (MacFarland scale). Bacteria 
$\left(2.0 \times 10^{7}\right.$ cells $\left./ \mathrm{mL}\right)$ were opsonized with $10 \%$ serum $(\mathrm{v} / \mathrm{v}$, final concentration) from healthy donors for $30 \mathrm{~min}$ at $37^{\circ} \mathrm{C}$ with constant and moderate agitation and used for the killing assay.

2.5.2. Bacterial Killing. Neutrophils $\left(2.0 \times 10^{6}\right.$ cells $/ \mathrm{mL}$ per assay) were suspended in RPMI 1640 and incubated with opsonized bacteria $\left(2.0 \times 10^{7}\right.$ cells $\left./ \mathrm{mL}\right)$ in a final volume of $1.0 \mathrm{~mL}$. Killing activity was monitored in the presence or absence of quercetin and naringenin $(25$ and $50 \mu \mathrm{M})$. The samples were maintained at $37^{\circ} \mathrm{C}$ with moderate shaking. Killing activity was determined by aseptically removing the samples at intervals of $0,30,60,90$, and $120 \mathrm{~min}$. These samples were then diluted in sterile distilled water $(1: 10)$, whirlmixed for $5 \mathrm{~min}$ to lyse neutrophils, and subsequently diluted in sterile saline $(1: 500)$. The number of viable bacteria was evaluated by spread-plating suitable diluted samples on nutrient agar and incubating them at $37^{\circ} \mathrm{C}$ for $24 \mathrm{~h}$ [21].

2.6. Statistical Analysis. Comparisons were made using oneway analysis of variance (ANOVA) and the Dunnett multiple comparisons test. The results are expressed as the mean \pm standard error of the mean (SEM) of at least three independent experiments. The data were analyzed using BioEstat 5.0 software. Values of $P<0.05$ were considered statistically significant.

\section{Results}

The present study investigated the antioxidant activity of naringenin and quercetin in three different systems of $\mathrm{HOCl}$ formation.

3.1. Cell-Free System: Direct HOCl Antioxidant Effects of Naringenin and Quercetin. In our first cell-free system, quercetin but not naringenin functioned as a $\mathrm{HOCl}$ scavenger. The scavenging action of quercetin depended on its concentration. Quercetin at a concentration of $50 \mu \mathrm{M}$ decreased $\mathrm{HOCl}$ by greater than $50 \%$ compared with the control group (Figure 1).

3.2. Cell-Free System: Effects of Naringenin and Quercetin on $\mathrm{HOCl}$ Production by $\mathrm{MPO} / \mathrm{H}_{2} \mathrm{O}_{2} / \mathrm{Cl}^{-}$. We also evaluated the effects of naringenin and quercetin in a cell-free system that contained $\mathrm{MPO} / \mathrm{H}_{2} \mathrm{O}_{2} / \mathrm{Cl}^{-}$. In this experimental model, $\mathrm{HOCl}$ is directly produced by the enzymatic system. Both quercetin and naringenin significantly and dose-dependently decreased $\mathrm{HOCl}$ production compared with the control group (Figure 2). Naringenin was less effective than quercetin in inhibiting $\mathrm{HOCl}$ formation, but this difference was not significant. A decrease in $\mathrm{HOCl}$ production by more than $60 \%$ was observed with the higher concentration of quercetin $(50 \mu \mathrm{M})$, whereas the decrease induced by naringenin was approximately $50 \%$ at the same concentration. One sample with 5-fluortryptamine (FTR), an MPO inhibitor [22], was assayed to compare the potential of the flavonoids as inhibitors of the chlorinating activity of MPO. The flavonoids were less effective than FTR.

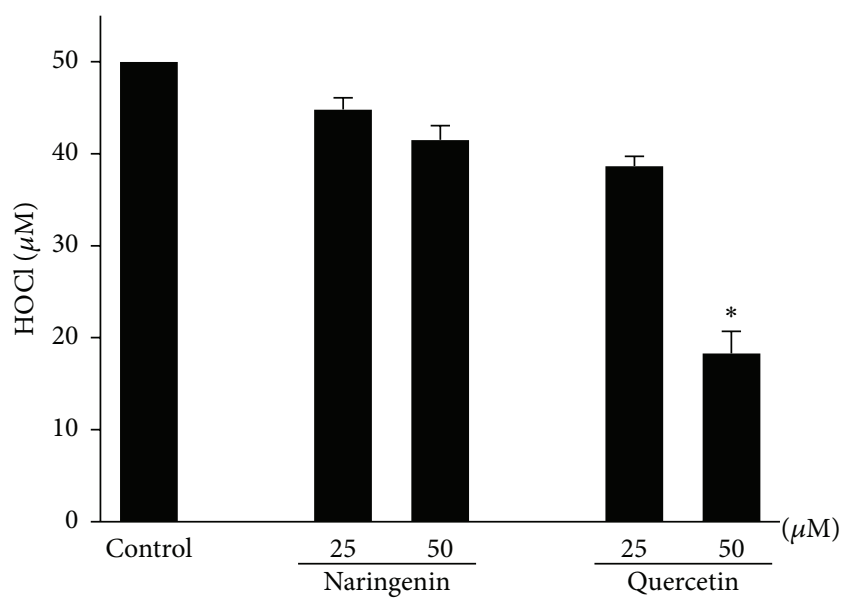

FIgURE 1: Antioxidant effects of naringenin and quercetin on $\mathrm{HOCl}$. A 96-well culture plate that contained $\mathrm{HOCl}(50 \mu \mathrm{M})$ and taurine $(5 \mathrm{mM})$ was incubated in the presence or absence of naringenin and quercetin $(25$ and $50 \mu \mathrm{M})$. The TMB solution $(50 \mu \mathrm{L})$ was then added to the samples, and $\mathrm{HOCl}$ was quantified. The data are expressed as the mean \pm SEM of three experiments. ${ }^{*} P<0.05$, compared with control group.

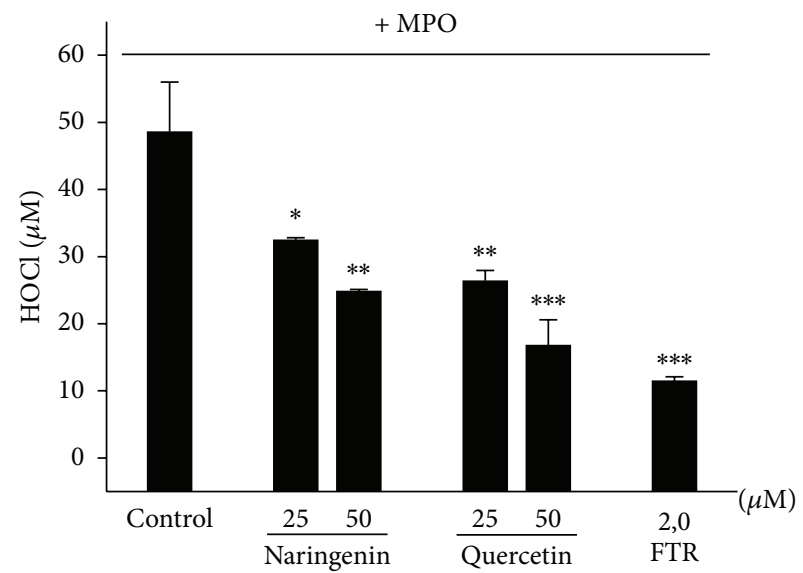

FIGURE 2: Effects of naringenin and quercetin on myeloperoxidase (MPO)-HOCl production. A 96-well culture plate that contained MPO $(65 \mathrm{nM})$, taurine $(5 \mathrm{mM})$, and $\mathrm{H}_{2} \mathrm{O}_{2}(50 \mu \mathrm{M})$ was incubated in the presence or absence of naringenin and quercetin $(25$ and $50 \mu \mathrm{M})$. The TMB solution $(50 \mu \mathrm{L})$ was then added to the samples, and $\mathrm{HOCl}$ production was quantified. The positive control (i.e., without the tested substances) was used to calculate the inhibitory effect. The data are expressed as the mean \pm SEM of three experiments. ${ }^{*} P<$ $0.05,{ }^{* *} P<0.005$, and ${ }^{* * *} P<0.001$, compared with control group.

3.3. Effects of Naringenin and Quercetin on HOCl Production by Neutrophils. To better understand the effects of naringenin and quercetin on $\mathrm{HOCl}$ formation, we assessed the effects of these compounds in a third system, PMA-activated neutrophils. As expected, both compounds inhibited $\mathrm{HOCl}$ production compared with the control (Figure 3). Quercetin exerted a strong inhibitory effect at both concentrations 


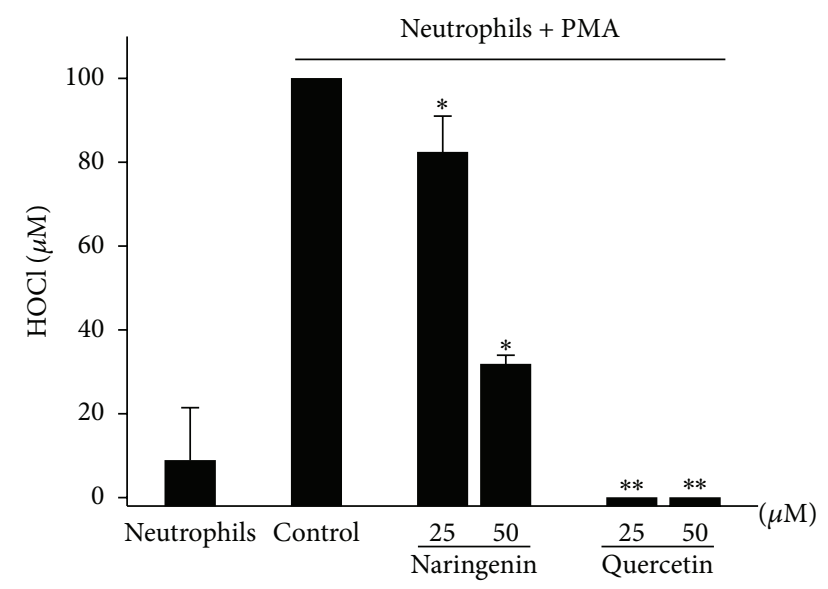

FIGURE 3: Effects of naringenin and quercetin on $\mathrm{HOCl}$ production by activated neutrophils. Neutrophils $\left(1.0 \times 10^{6}\right.$ cells $\left./ \mathrm{mL}\right)$ were preincubated in the presence or absence of naringenin and quercetin ( 25 and $50 \mu \mathrm{M}$ ) with $5 \mathrm{mM}$ taurine. All of the samples were then incubated with PMA $(6.65 \mu \mathrm{g} / \mathrm{mL})$. The TMB solution $(50 \mu \mathrm{L})$ was then added to the samples, and $\mathrm{HOCl}$ production was quantified. The data are expressed as the mean \pm SEM of three experiments. ${ }^{*} P<0.05,{ }^{* *} P<0.01$ compared with control group.

tested, causing approximately $100 \%$ decreases in $\mathrm{HOCl}$ production. However, naringenin exerted a significant effect only at $50 \mu \mathrm{M}$, inhibiting $\mathrm{HOCl}$ production by approximately $60 \%$.

\subsection{Effects of Naringenin and Quercetin on ROS Production} by Leukocytes. As a second step, we compared the ability of quercetin and naringenin to inhibit intracellular ROS production assessed by flow cytometry, in which the nonfluorescent DHR is oxidized by ROS, producing fluorescent rhodamine. Again, quercetin was more efficient than naringenin (Figure 4). Quercetin at both tested concentrations inhibited ROS by more than $80 \%$. Naringenin at higher concentrations inhibited ROS by approximately $50 \%$.

\subsection{Effects of Naringenin and Quercetin on Microbicidal} Activity. We showed that quercetin and, to a lesser extent, naringenin affected $\mathrm{HOCl}$ production by PMA-activated neutrophils. $\mathrm{HOCl}$ is a toxic metabolite responsible for the microbicidal activity of phagocytes $[14,15]$. We expected that these compounds would have different effects on neutrophil microbicidal activity. Thus, we studied the effects of these flavonoids on the microbicidal activity of neutrophils by spread-plating $S$. aureus onto a nutrient-agar medium after incubation with neutrophils. In contrast to the previous results of the present study mentioned above, both quercetin and naringenin $(25$ and $50 \mu \mathrm{M})$ completely inhibited neutrophil microbicidal activity compared with the control group (Figure 5).

\section{Discussion}

Numerous compounds with potential antioxidant effects and promising activity against many human diseases associated with oxidative damage have been studied over the past years $[23,24]$. These compounds include naringenin and quercetin, two flavonoids with antioxidant effects that act as ROS scavengers $[11,12]$ and inhibit the activity of ROS-forming enzymes (e.g., NADPH oxidase) [13]. However, no reports have described their action on the microbicidal response of neutrophils. The microbicidal activity of phagocytes is well known to depend on ROS, and $\mathrm{HOCl}$ plays an important role in this process [25]. The present study sought to further elucidate the effects of naringenin and quercetin on the neutrophil response, especially with regard to microbicidal activity.

We first investigated the antioxidant effects of naringenin and quercetin on $\mathrm{HOCl}$ production by cellular and cellfree systems. The effects of naringenin observed in the MPO model and in PMA-activated neutrophils, compared with the first cell-free system, indicated that significant inhibition of MPO chlorinating activity can be induced by this compound. The production of $\mathrm{HOCl}$ might be reduced in the presence of flavonoids that act as MPO inhibitors [26]. Thus, the $15 \%$ (cell-free system) to $50 \%$ (MPO system) increases in the inhibition of $\mathrm{HOCl}$ production induced by $50 \mu \mathrm{M}$ naringenin might be related to direct inhibition of MPO chlorinating activity. Quercetin exhibited the same pattern of inhibition in the cell-free systems, suggesting that quercetin is a better scavenger of $\mathrm{HOCl}$ and poor inhibitor of MPO. Quercetin also markedly inhibited $\mathrm{HOCl}$ production in PMA-activated neutrophils. In this system, PMA activated the NADPH oxidase complex, which is responsible for the production of superoxide anions and, after a cascade of reactions, produces $\mathrm{H}_{2} \mathrm{O}_{2}$ and $\mathrm{HOCl}$ [27]. Therefore, quercetin, a well-known antioxidant, could react with all ROS formed in the cellular system, consequently disrupting $\mathrm{HOCl}$ formation through a scavenging effect $[11,12]$. To support this possibility, the DHR assay confirmed that quercetin is an efficient scavenger of ROS generated by activated neutrophils.

We showed that naringenin and quercetin also inhibited the microbicidal activity of neutrophils. These results may reflect the antioxidant activity of these compounds, which consume both $\mathrm{HOCl}$ and ROS precursors of $\mathrm{HOCl}$, thus inhibiting the formation of $\mathrm{HOCl}$ derivatives with high microbicidal activity, such as singlet oxygen. The suppression of these ROS induced a direct effect on microbicidal activity [28].

In conclusion, the flavonoids naringenin and quercetin exert their effects by controlling the effector mechanisms of ROS production, which might be seen as a positive effect when considering the importance of antioxidant agents in oxidative stress conditions or a negative effect when considering the importance of ROS for microbicidal activity. The latter interpretation is the highlight of the present study. Previous studies suggested that an increase in basal antioxidant capacity can contribute to the development of certain cancers $[9,29]$. DeNicola et al. [30] provided evidence that several oncogenes actively upregulate physiological antioxidant enzymes, promoting a ROS detoxification program that is required for tumor initiation. These results challenge the traditional view that the greater intake of antioxidants is 


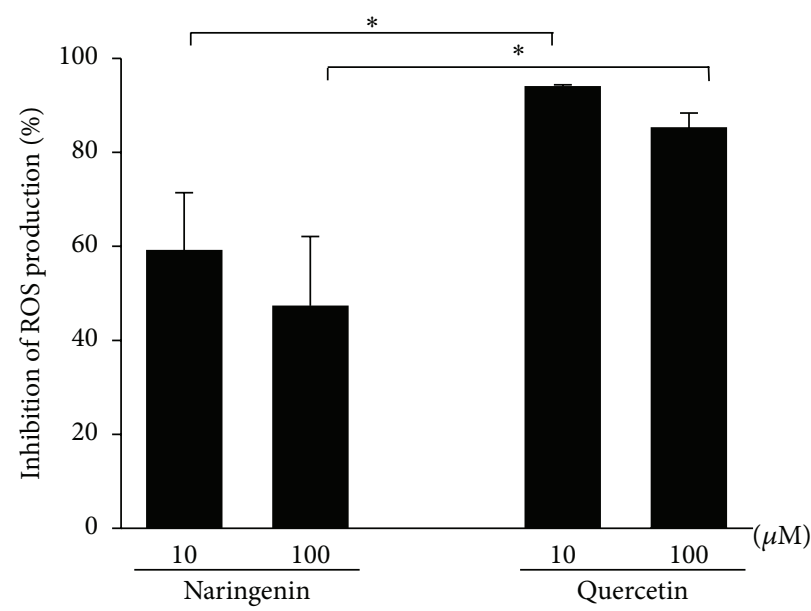

(a)

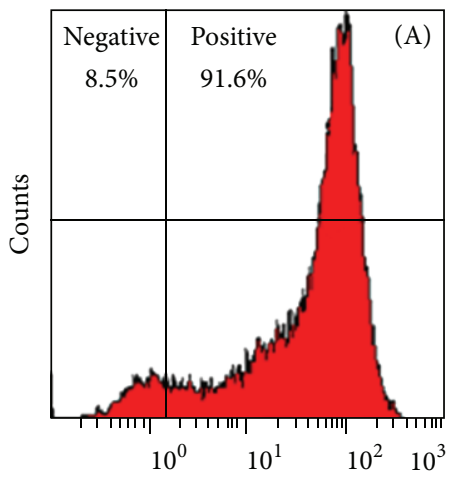

$\mathrm{Rh} 123$ fluorescence

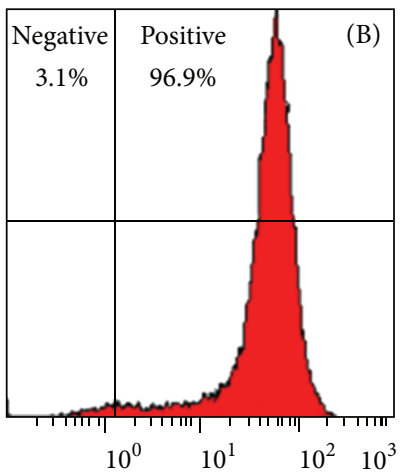

$\mathrm{Rh} 123$ fluorescence

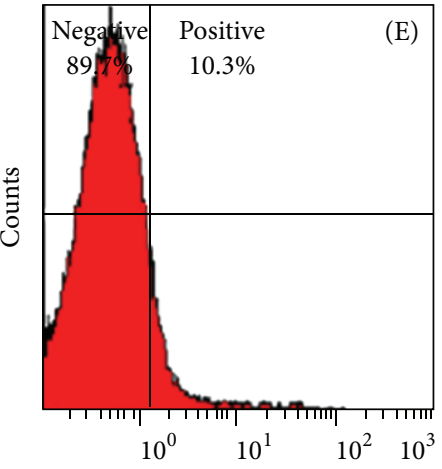

$\mathrm{Rh} 123$ fluorescence

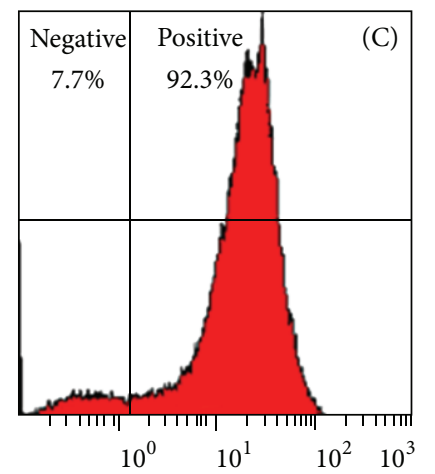

Rh 123 fluorescence

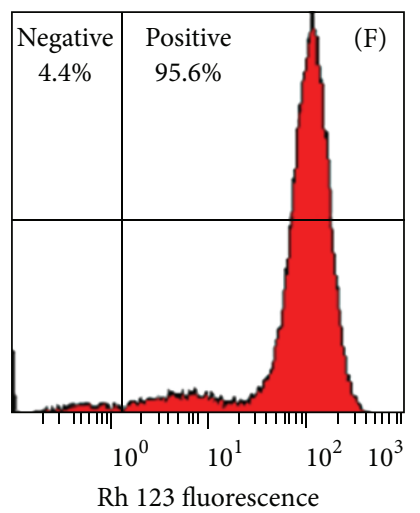

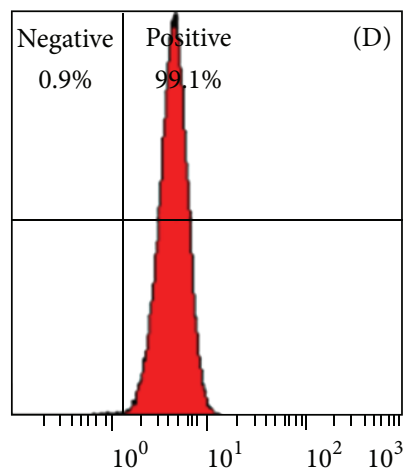

$\mathrm{Rh} 123$ fluorescence

(b)

FIGURE 4: Effects of naringenin and quercetin on ROS production by neutrophils. (a) Neutrophils were preincubated in the presence or absence of naringenin and quercetin $(10$ and $100 \mu \mathrm{M})$ and stimulated with PMA (400 nM), and intracellular ROS production was determined by flow cytometry using DHR as a probe. (b) Representative histograms are shown in logarithmic scale. Neutrophils were preincubated in the presence of naringenin $10 \mu \mathrm{M}(\mathrm{A})$ and $100 \mu \mathrm{M}(\mathrm{B})$ and activated with PMA. Neutrophils were preincubated in the presence of quercetin $10 \mu \mathrm{M}(\mathrm{C})$ and $100 \mu \mathrm{M}$ (D) and activated with PMA. Neutrophils (negative control) (E); neutrophils activated with PMA (positive control) (F). The percentage of inhibition of ROS production by naringenin and quercetin was calculated and compared with the positive group. The data are expressed as the mean \pm SEM of four experiments. ${ }^{*} P<0.05,10 \mu \mathrm{M}$ naringenin versus $10 \mu \mathrm{M}$ quercetin and $100 \mu \mathrm{M}$ naringenin versus $100 \mu \mathrm{M}$ quercetin. 


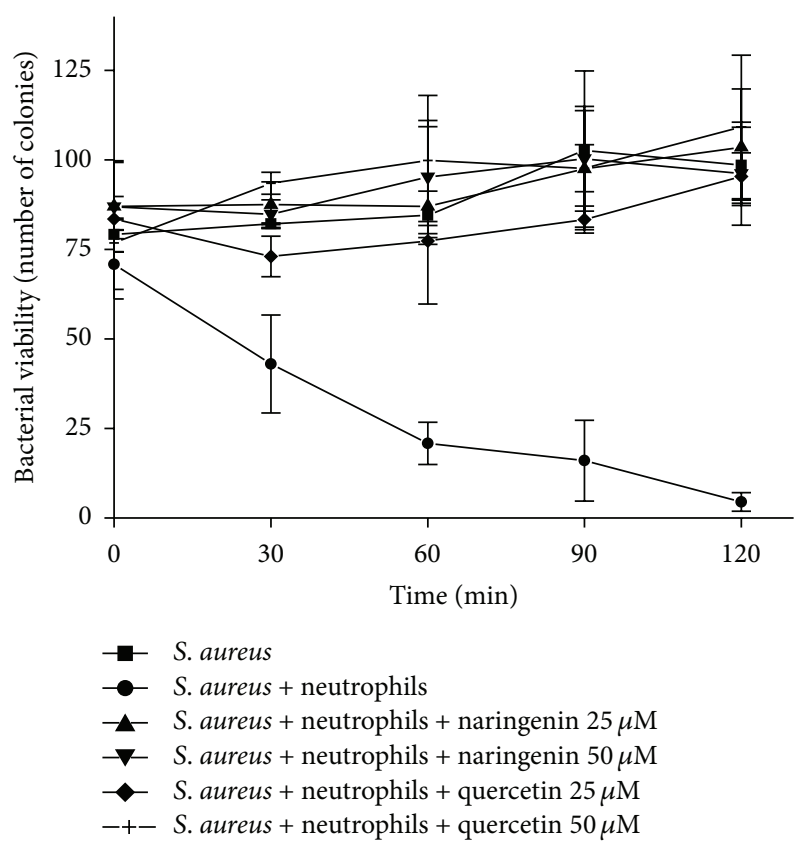

FIGURE 5: Effects of naringenin and quercetin on the kinetics of the killing of $S$. aureus by neutrophils. Neutrophils $(2.0 \times$ $10^{6}$ cells $/ \mathrm{mL}$ per assay) were incubated with opsonized bacteria $\left(2.0 \times 10^{7}\right.$ cells $\left./ \mathrm{mL}\right)$. Microbicidal activity was monitored in the presence and absence of $25 \mu \mathrm{M}(\boldsymbol{\Delta})$ and $50 \mu \mathrm{M}(\boldsymbol{\nabla})$ naringenin and $25 \mu \mathrm{M}(\downarrow)$ and $50 \mu \mathrm{M}(+)$ quercetin. Killing activity was determined by aseptically removing the samples at intervals of $0,30,60,90$, and $120 \mathrm{~min}$. The number of viable bacteria was evaluated by spreadplating suitable diluted samples on nutrient agar. The controls included bacteria alone $(\boldsymbol{\square})$ and bacteria plus neutrophils $(\bullet)$. The data are expressed as the mean \pm SEM of three experiments.

always associated with improvements in pathological conditions [31, 32]. This view must be revisited, especially with regard to infectious diseases and the development of certain cancers.

\section{Conflict of Interests}

There is no conflict of interests declared by the authors.

\section{Acknowledgments}

This study was supported by Conselho Nacional de Desenvolvimento Científico e Tecnológico (CNPq), Coordenação de Aperfeiçoamento de Pessoal de Nível Superior (Capes), and Fundação Araucária.

\section{References}

[1] M. J. Morgan and Z.-G. Liu, "Reactive oxygen species in TNF $\alpha$ induced signaling and cell death," Molecules and Cells, vol. 30, no. 1, pp. 1-12, 2010.

[2] B. C. Dickinson and C. J. Chang, "Chemistry and biology of reactive oxygen species in signaling or stress responses," Nature Chemical Biology, vol. 7, no. 8, pp. 504-511, 2011.
[3] A. Rizzo, M. T. Roscino, F. Binetti, and R. L. Sciorsci, "Roles of reactive oxygen species in female reproduction," Reproduction in Domestic Animals, vol. 47, no. 2, pp. 344-352, 2012.

[4] J.-S. Kim, T. Y. Huang, and G. M. Bokoch, "Reactive oxygen species regulate a slingshot-cofilin activation pathway," Molecular Biology of the Cell, vol. 20, no. 11, pp. 2650-2660, 2009.

[5] B. C. Dickinson, J. Peltier, D. Stone, D. V. Schaffer, and C. J. Chang, "Nox2 redox signaling maintains essential cell populations in the brain," Nature Chemical Biology, vol. 7, no. 2, pp. 106-112, 2011.

[6] A. L. P. Chapman, M. B. Hampton, R. Senthilmohan, C. C. Winterbourn, and A. J. Kettle, "Chlorination of bacterial and neutrophil proteins during phagocytosis and killing of Staphylococcus aureus," The Journal of Biological Chemistry, vol. 277, no. 12, pp. 9757-9762, 2002.

[7] R. S. Frey, M. Ushio-Fukai, and A. B. Malik, "NADPH oxidasedependent signaling in endothelial cells: role in physiology and pathophysiology," Antioxidants \& Redox Signaling, vol. 11, no. 4, pp. 791-810, 2009.

[8] S. C. Correia, R. X. Santos, G. Perry, X. Zhu, P. I. Moreira, and M. A. Smith, "Mitochondrial importance in Alzheimer's, Huntington's and Parkinson's diseases," Advances in Experimental Medicine and Biology, vol. 724, pp. 205-221, 2012.

[9] P. Lonkar and P. C. Dedon, "Reactive species and DNA damage in chronic inflammation: reconciling chemical mechanisms and biological fates," International Journal of Cancer, vol. 128, no. 9, pp. 1999-2009, 2011.

[10] A. K. Tiwari, "Antioxidants: new-generation therapeutic base for treatment of polygenic disorders," Current Science, vol. 86, no. 8, pp. 1092-1102, 2004.

[11] F. Ursini, M. Maiorino, P. Morazzoni, A. Roveri, and G. Pifferi, "A novel antioxidant flavonoid (IdB 1031) affecting molecular mechanisms of cellular activation," Free Radical Biology and Medicine, vol. 16, no. 5, pp. 547-553, 1994.

[12] G. Agati, E. Azzarello, S. Pollastri, and M. Tattini, "Flavonoids as antioxidants in plants: location and functional significance," Plant Science, vol. 196, pp. 67-76, 2012.

[13] M. Ciz, P. Denev, M. Kratchanova, O. Vasicek, G. Ambrozova, and A. Lojek, "Flavonoids inhibit the respiratory burst of neutrophils in mammals," Oxidative Medicine and Cellular Longevity, vol. 2012, Article ID 181295, 6 pages, 2012.

[14] L. Wang, M. Bassiri, R. Najafi et al., "Hypochlorous acid as a potential wound care agent," Journal of Burns and Wounds, vol. 6, no. 5, pp. 65-79, 2007.

[15] L. Gebicka and E. Banasiak, "Hypochlorous acid-induced heme damage of hemoglobin and its inhibition by flavonoids," Toxicology in Vitro, vol. 26, no. 6, pp. 924-929, 2012.

[16] M. Valko, D. Leibfritz, J. Moncol, M. T. D. Cronin, M. Mazur, and J. Telser, "Free radicals and antioxidants in normal physiological functions and human disease," The International Journal of Biochemistry and Cell Biology, vol. 39, no. 1, pp. 44-84, 2007.

[17] A. Bøyum, "Isolation of lymphocytes, granulocytes and macrophages," Scandinavian Journal of Immunology, vol. 5, pp. 9-15, 1976.

[18] A. Böyum, "Isolation of leucocytes from human blood. A twophase system for removal of red cells with methylcellulose as erythrocyte-aggregating agent," Scandinavian Journal of Clinical and Laboratory Investigation, Supplement, vol. 97, pp. 9-29, 1968.

[19] J. M. Dypbukt, C. Bishop, W. M. Brooks, B. Thong, H. Eriksson, and A. J. Kettle, "A sensitive and selective assay for chloramine 
production by myeloperoxidase," Free Radical Biology and Medicine, vol. 39, no. 11, pp. 1468-1477, 2005.

[20] J. P. Crow, "Dichlorodihydrofluorescein and dihydrorhodamine 123 are sensitive indicators of peroxynitrite in vitro: implications for intracellular measurement of reactive nitrogen and oxygen species," Nitric Oxide: Biology and Chemistry, vol. 1, no. 2, pp. 145-157, 1997.

[21] M. B. Hampton and C. C. Winterbourn, "Methods for quantifying phagocytosis and bacterial killing by human neutrophils," Journal of Immunological Methods, vol. 232, no. 1-2, pp. 15-22, 1999.

[22] M. L. Zeraik, V. F. Ximenes, L. O. Regasini et al., " 4 ' Aminochalcones as novel inhibitors of the chlorinating activity of myeloperoxidase," Current Medicinal Chemistry, vol. 19, no. 31, pp. 5405-5413, 2012.

[23] H. Yagi, J. Tan, and R. S. Tuan, "Polyphenols suppress hydrogen peroxide-induced oxidative stress in human bone-marrow derived mesenchymal stem cells," Journal Cellular Chemistry, vol. 28, pp. 1-38, 2012.

[24] M. Zhang, S. G. Swarts, L. Yin et al., "Antioxidant properties of quercetin," Advances in Experimental Medicine and Biology, vol. 701, pp. 283-289, 2011.

[25] C. C. Winterbourn, M. B. Hampton, J. H. Livesey, and A. J. Kettle, "Modeling the reactions of superoxide and myeloperoxidase in the neutrophil phagosome: implications for microbial killing," The Journal of Biological Chemistry, vol. 281, no. 52, pp. 39860-39869, 2006.

[26] V. A. Kostyuk, T. Kraemer, H. Sies, and T. Schewe, "Myeloperoxidase/nitrite-mediated lipid peroxidation of low-density lipoprotein as modulated by flavonoids," FEBS Letters, vol. 537, no. 1-3, pp. 146-150, 2003.

[27] J. M. Robinson, "Reactive oxygen species in phagocytic leukocytes," Histochemistry and Cell Biology, vol. 130, no. 2, pp. 281297, 2008.

[28] C. C. Winterbourn and A. J. Kettle, "Redox reactions and microbial killing in the neutrophil phagosome," Antioxidants \& Redox Signaling, vol. 18, no. 6, pp. 642-660, 2013.

[29] D. Trachootham, J. Alexandre, and P. Huang, "Targeting cancer cells by ROS-mediated mechanisms: a radical therapeutic approach?" Nature Reviews Drug Discovery, vol. 8, no. 7, pp. 579-591, 2009.

[30] G. M. DeNicola, F. A. Karreth, T. J. Humpton et al., "Oncogeneinduced Nrf2 transcription promotes ROS detoxification and tumorigenesis," Nature, vol. 475, no. 7354, pp. 106-110, 2011.

[31] S. C. Bischoff, "Quercetin: potentials in the prevention and therapy of disease," Current Opinion in Clinical Nutrition and Metabolic Care, vol. 11, no. 6, pp. 733-740, 2008.

[32] Z.-P. Xiao, Z.-Y. Peng, M.-J. Peng, W.-B. Yan, Y.-Z. Ouyang, and H.-L. Zhu, "Flavonoids health benefits and their molecular mechanism," Mini-Reviews in Medicinal Chemistry, vol. 11, no. 2, pp. 169-177, 2011. 


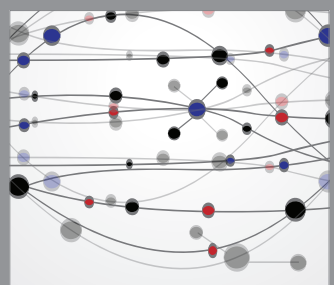

The Scientific World Journal
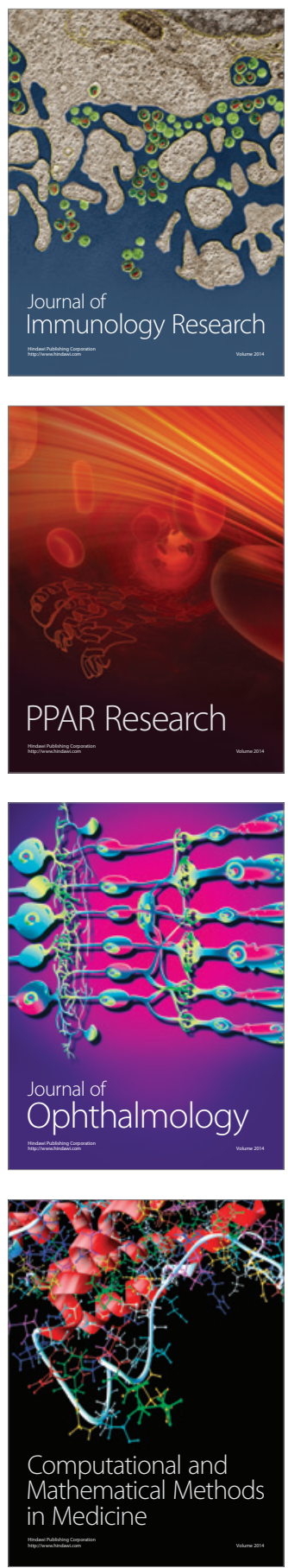

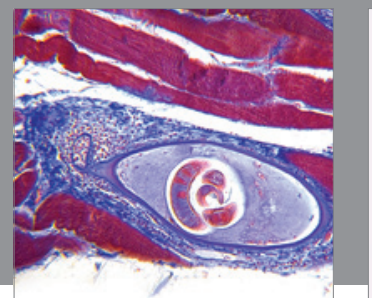

Gastroenterology

Research and Practice
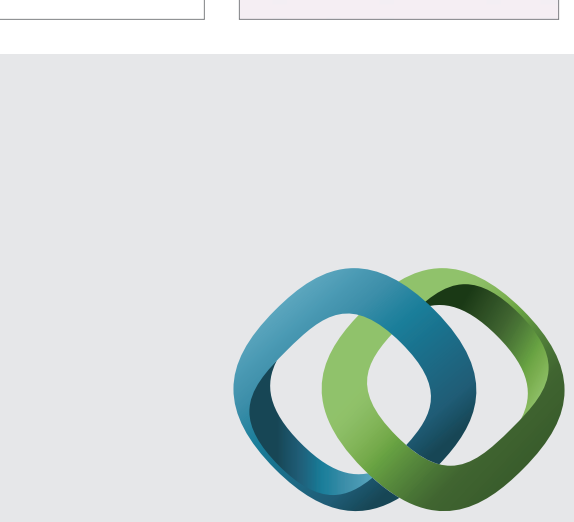

\section{Hindawi}

Submit your manuscripts at

http://www.hindawi.com
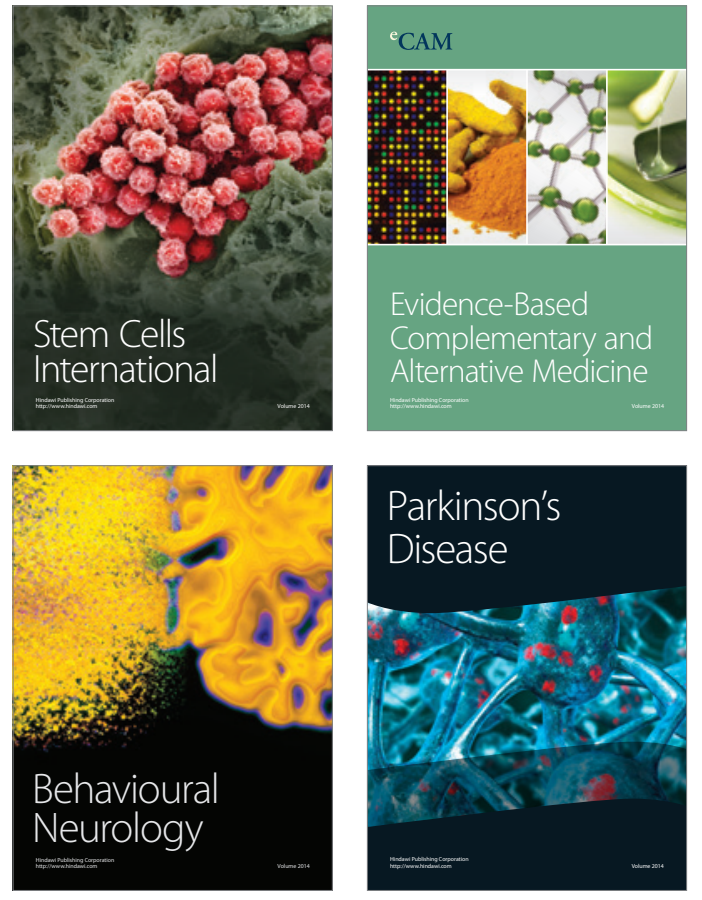
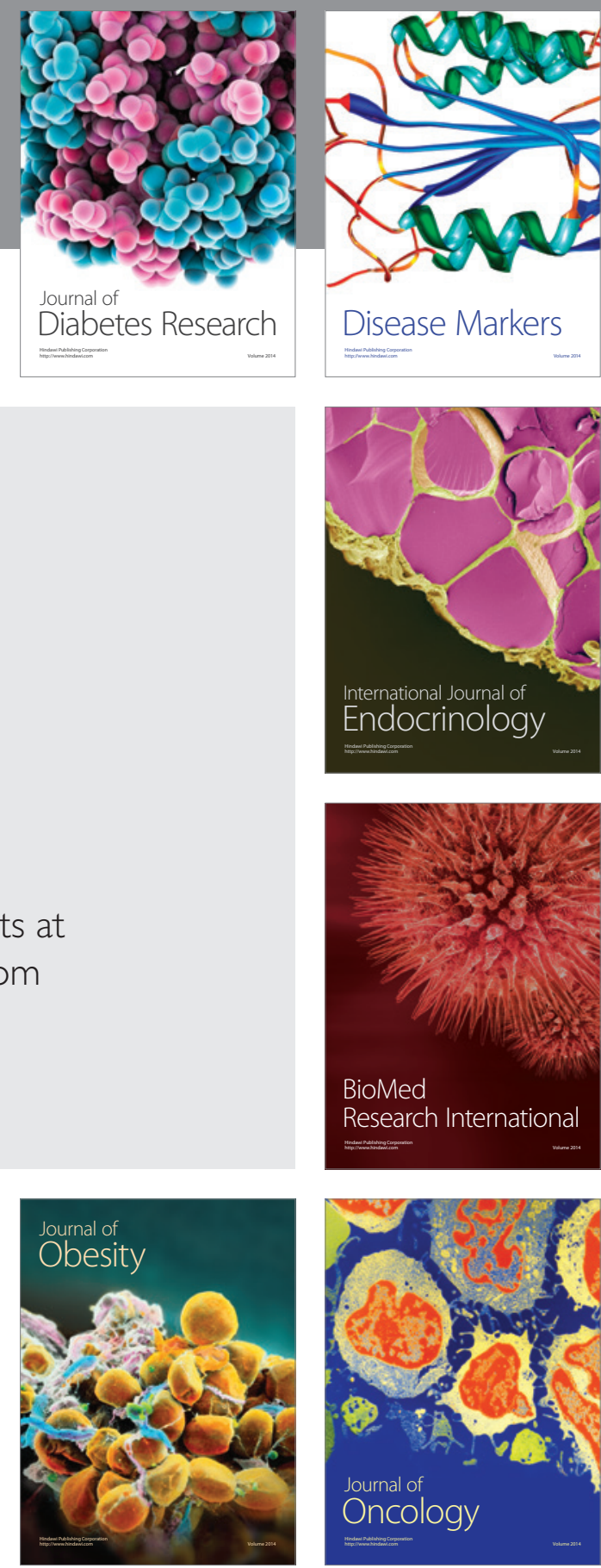

Disease Markers
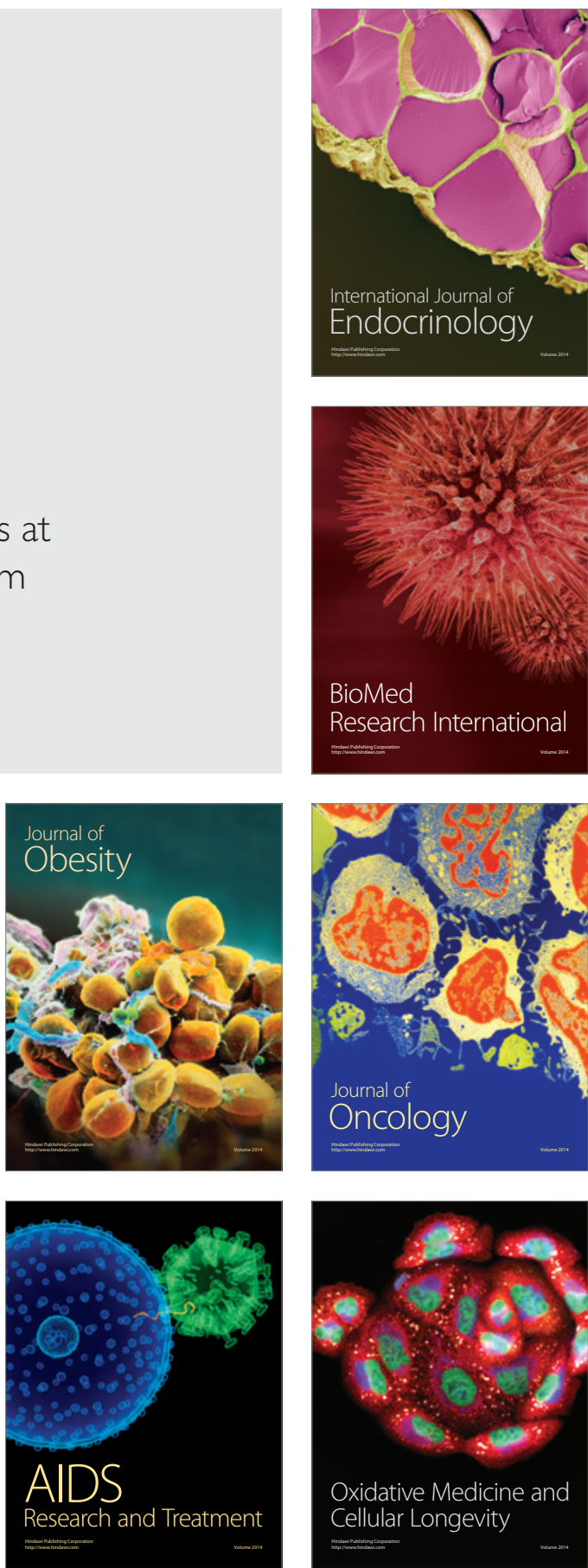